\title{
Golden Proportion and Golden Standard Assessment of Maxillary Anterior Teeth Among Undergraduate Students"
}

\author{
Danish Shahnawaz ${ }^{1}$ \\ BDS \\ Hira Akhtar ${ }^{2}$ \\ BDS \\ Ziaullah Choudry \\ BDS, MSc \\ Farah $\mathrm{Naz}^{4}$ \\ BDS, FCPS \\ Arshad Hassan ${ }^{5}$ \\ BDS, FCPS \\ Javeria Ali Khan ${ }^{6}$ \\ BDS, FCPS
}

OBJECTIVE: Dental esthetics is a prime consideration for all patients. While restoring teeth, high importance should be given to the size and shape of teeth for better esthetic results. Various proportions have been recommended to describe the relationship between maxillary anterior teeth. Golden Proportion and Golden Standard are two ratios most commonly used. The purpose of this study was to evaluate the golden proportion and golden standard in maxillary anterior teeth among Pakistani undergraduate students.

METHODOLOGY: A cross sectional study, conducted in the department of Operative Dentistry at Dental Section of Dow International Medical College (Dow University of Health Sciences). One hundred students (28 males and 72 females) meeting the inclusion criteria were selected, their dental casts were analyzed for actual width and length and apparent width by digital caliper. From these measurements golden standard and golden proportion were calculated.

RESULTS: Mean value of golden standard was found to be $0.82(82 \%, \mathrm{p}=0.04)$ as compared to the ideal standard value of $80 \%$. Mean value of golden proportion was found to be $1.67(\mathrm{p}=2.09 \mathrm{X} 10-7)$

CONCLUSION: Within the confines of this study, Golden Proportion and Golden Standard were not found to exist in the sample Pakistani population.

KEY WORDS: Golden Proportion (GP), Golden Standard (GP), Tooth proportion, Maxillary Anterior teeth, Esthetic.

HOW TO CITE: Shahnawaz D, Akhtar H, Choudry Z, Naz F, Hasan A, Khan JA. Golden proportion and golden standard assessment of maxillary anterior teeth among undergraduate students". J Pak Dent Assoc 2019;28(2):74-77.

DOI: https://doi.org/10.25301/JPDA.282.74

Received: 29 January 2019, Accepted: 06 March 2019

\section{INTRODUCTION}

$\mathrm{D}$ ental esthetics is a prime consideration for all patients. The size and shape of the maxillary anterior teeth have significant affect not only on the dental esthetics, but also on the overall facial esthetics of a person. ${ }^{1}$ A mismatch between size and shape of restored teeth and the facial symmetry, may lead to patient developing psychological and social problems. ${ }^{2}$ To provide a restoration which is esthetically pleasing and good, various maxillary anterior teeth proportions have been recommended. These

1. MDS Trainee, Department of Operative Dentistry, DIKIOHS, DUHS

2. Lecturer, Department of Operative Dentistry, DIKIOHS, DUHS

3. Associate Professor, Department of Prosthodontics, DIKOHS, DUHS

4. Professor, Department of Operative Dentistry, Dental section, DIMC, DUHS

5. Professor, Department of Operative Dentistry, DDC, DUHS.

6. Assistant Professor, Department of Operative Dentistry, DDC, DUHS

Corresponding author: "Dr Farah Naz" < farah.naz@duhs.edu.pk > include; golden proportion, golden standard, golden percentage, recurring esthetic dental proportion and Chu's proportion. ${ }^{3}$

Recurring Esthetic Proportion (RED) proposes that the consecutive sizes of the teeth follow a constant ratio, when succeeding distally from the midline. $8 \mathrm{Chu}$ suggested a fixed difference in the size of maxillary anterior teeth. ${ }^{3}$ Golden percentage is a two-sided measurement of each tooth dimension as a percentage of the total six anterior teeth. ${ }^{3}$ All these parameters represent a balanced and harmonious smile design. ${ }^{4}$ Of all the ratios the two most commonly used and researched dental proportions are golden proportion and golden standard.

The application of the "golden proportion (GP)" is considered a keystone of smile design theory. ${ }^{4}$ Lombardi identified GP as an important tool in determining the anterior teeth width for their restoration. It was first applied in dental 
aesthetic by Levin, who suggested that apparent width of central and lateral incisor should be in GP to that of their adjacent teeth when viewed from the front. ${ }^{5}$ Levin was the pioneer advocate of applying GP value to dental aesthetics, he proposed that when the face was viewed from the front, the apparent width of the central incisor should be 0.618 to the width of the lateral incisor and the lateral incisor should be in 0.618 to the width of the canine. 4 The existing value of 0.618 is regarded as the "golden proportion value". ${ }^{4}$

Golden Standard (GS) is defined as the ideal width to height ratio of an individual tooth.6 According to this ratio, the width of an anterior tooth should be $80 \%$ of its height. If this ratio is higher, it means teeth are wider; a lower ratio signifies longer teeth. ${ }^{2,7}$

Numerous studies have been performed throughout the world on various racial and ethnic groups to assess the existence and variation in dental proportions. ${ }^{9,6,10,11}$ Locally, the data is still scarce regarding dental proportion esthetic norms of Pakistani Population.

This study is the first research performed on Pakistani population to assess the existence of GP and GS. The purpose of the study was to evaluate the golden proportion and standard in the anterior teeth among undergraduate Pakistani students.

\section{METHODOLGY}

This cross sectional study was conducted in the Operative Dentistry department at Dental Section of Dow International Medical College, Dow University of Health Sciences for a period of 6 months from October 2014 till March 2015. Total sample size of 100 was calculated using PASS version II, one sample t-test with $95 \%$ confidence interval, $99 \%$ power of test with a mean difference of p-value of 0.05 and standard deviation of $0.069{ }^{6}$

One hundred undergraduate students including 28 males and 72 females were selected using non-probability purposive sampling technique. Participants within the age range of 18-23 years, with no missing anterior teeth, sound gingival and periodontal conditions with no interdental spacing, rotation and/or crowding and no history of orthodontic treatment were included in the study. Participants having maxillary anterior teeth with an evidence of gingival alteration, dental irregularities, apparent loss of tooth structure due to attrition, fracture, caries, restorations or anterior prosthesis and any developmental facial and dental defects were excluded.

Ethical approval was taken from the ethical review committee (IRB) of Dow university of Health Sciences (Reference Letter No. REG/IRB 1001/DUHS/approval/2018/52). After obtaining signed informed consents from all participants, dental impression of each subject was obtained by Alginate (Tulip, CavexHolland) and cast was made by Dental Stone (GarrecoUSA). Measurement for actual width and length of each individual tooth and apparent width of each individual tooth (from maxillary right canine to left canine) was taken with the help of digital Vernier caliper (Hornady-USA) with a least count of $0.01 \mathrm{~mm}$. Data analysis of each individual maxillary tooth was documented on pre-designed working form.

Golden Proportion (GP) of each individual tooth from central incisor to canine (both right and left sides) was determined. Mean of all these values for an individual were taken for analysis. Assessments of GP were conducted by drawing vertical lines. This was achieved by placing the casts on a flat surface. The perceived mesio-distal widths of the teeth were marked according to eye level when viewed from front (Figure 1). Measurements for the spaces in the lines was calculated using the digital caliper. The formula used was

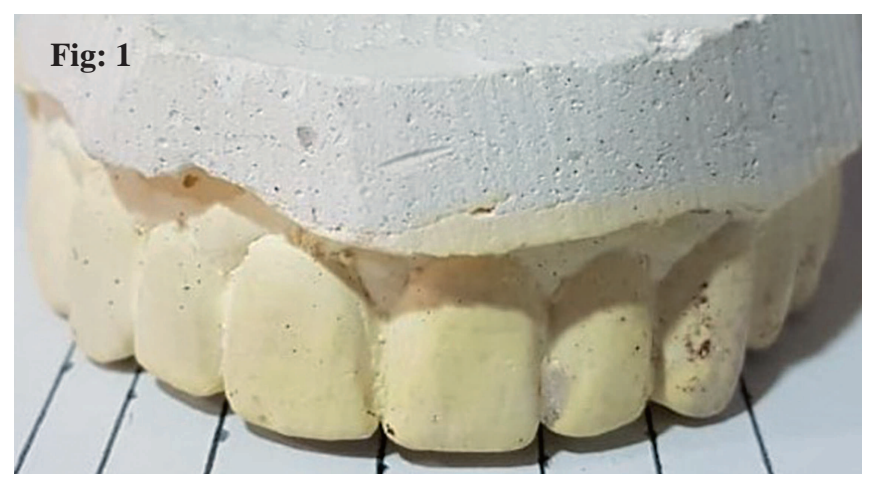

Golden proportion $=\underline{a+b} / a$ as devised by Levin ${ }^{4}$ Where,

$a$ : actual width of mesial tooth

$b$ : apparent width of lateral tooth

GS of each individual tooth from central incisor to canine of both right and left sides was determined by measuring actual length from incisal edge to the gingival line and width from the mesial contact angle to the distal contact angle. The width /length ratio was calculated for each tooth and mean was taken.

Data analysis was done on SPSS version 16 (Chicago, IL) with level of significance $\alpha=0.05$ at $95 \%$ confidence interval. Independent sample t-test was used to find the difference in Male to Female ratio, one sample t-test was applied for golden standard and Sign test for golden proportion.

\section{RESULTS}

In present study out of 100 participants including 28 
males and 72 females, males presented a GS value of $80.2 \%$ which is nearer to the ideal GS value (80\%) as compared to females presented a value of $83.03 \%$. Male to Female ratio was found to be insignificant as seen in Table I. Mean value

Table I: Male to Female Ratio of Golden Standard (GS)

\begin{tabular}{|c|c|c|c|c|}
\hline Gender & \multicolumn{1}{c}{$N$} & \multicolumn{1}{c}{ Mean } & Std. Deviation (SD) & p-value \\
\hline Male & 28 & 0.8020 & 0.08719 & 0.249 \\
\hline Female & 72 & 0.8303 & 0.07290 & 0.294 \\
\hline
\end{tabular}

Table II: Mean values of Golden Standard (GS) and Golden Proportion(GP)

\begin{tabular}{|c|c|c|c|c|}
\hline $\begin{array}{c}\text { Dental Parameter } \\
\text { Golden Standard } \\
\text { (GS) }\end{array}$ & 100 & 0.8224 & 0.07732 & 0.04 \\
\hline $\begin{array}{c}\text { Golden Proportion } \\
\text { (GP) }\end{array}$ & 100 & 1.6694 & 0.14734 & $2.09 \times 10^{-7}$ \\
\hline
\end{tabular}

of GS was significant and calculated to be 0.82 (82\%, $\mathrm{p}$-value $=0.04)$ as seen in Table II. Mean value of GP was recorded as $1.67\left(\mathrm{P}\right.$-value $\left.=2.09 \times 10^{-7}\right)$ which is highly significant when compared to ideal GP value of 1.62 ; as shown in Table II.

\section{DISCUSSION}

Dental esthetics is dependent upon numerous factors and their inter-relationships. Although information concerning GP is important for clinicians when working within the esthetic zone, racial differences should be taken into regard. Esthetic proportions need to be adapted in accordance to these differences. The key aesthetic determinant is the size and morphology of central incisor. Previous studies have used extracted teeth for measuring tooth size but nowadays pictures and casts are more commonly used. ${ }^{1}$ The results of the present study showed that male have more pleasing GP and GS as compared to female participants. Males presented a golden standard value of $80.2 \%$ as compared to $83 \%$ for female, signifying females have squarer teeth. GP ratio in present study was calculated to be 1.67 ; this result is supported by the studies conducted by Ong and Mahshid who also found that the prevalence of the golden proportion had not been an influential factor of determining dental attractiveness. ${ }^{9,13}$

The results of the present study are different when compared to the ideal ratio of $80 \%$, which is documented in literature as golden standard. The results of the present study are in contrast to results conducted in Turkish population, they reported the width-to-height ratios percentages of 76-
$86 \%$ in both genders1. This determines that maxillary anterior teeth in Pakistani population are narrower compared to Turkish population but this can be attributed to differences in racial characteristics. Another study by Al-Marook, Majeed et al reported that GP and GS values did not exist in the sample Malaysian population. ${ }^{6}$ On the other hand similar results to present study were recorded by Wolfart ${ }^{14}$ who reported a width-to-length proportion of $82 \%$ in German population.

In 2010, a novel pilot study evaluating GP was conducted on the Pakistani population, this study concluded that GP should not be considered as a significant factor of defining dental desirability. It should be a range other than a particular value. ${ }^{12}$ Similar conclusion was reported by Parnia and Hafezeqoran they reported no significant difference between proportions of width-to-height of central incisors and GS in Irani population. ${ }^{15}$

There is no concrete evidence that supports GP as an essential or ideal esthetic standard that mandates consideration when creating space for replacement of missing lateral incisors. ${ }^{16,17}$ Alhabahbah et al evaluated the validity of mathematical proportion that between the maxillary anterior teeth widths. ${ }^{18}$ They found that the mean perceived widths of anterior teeth were significantly larger for males compared to females. This result is quite contrary to what we found in our study; moreover, the GP did not exist between the perceived widths of maxillary anterior teeth. ${ }^{18}$ The difference in results may be attributed to variations in regional perception of aesthetics. In 2018, Al-Kaisay and Garib studied Kurdish and Arab populations ${ }^{19}$, they reported GP to exist between apparent widths of lateral and central incisors but not for lateral incisors and canines. Furthermore, no ideal ratio of width and height was found in this study, which is similar to our study in case of female participants.

As mentioned earlier, several studies have been conducted and a consensus is reached that in order to achieve harmony among tooth lengths, GP should not be used as a singular ratio to produce a satisfactory appearance rather it should be taken as a range. ${ }^{9,20,21}$ In order to attain an esthetic result, discovery of a geometrical and mathematical relationship between anterior teeth is important. A statistically reliable value explained in the form of range to support the existing theories on esthetic parameter would be more clinically applicable for dental practitioners. ${ }^{22}$

It is our recommendation that further studies should be carried out on a larger sample with equal male to female ratio; in order to assess any gender difference really exists. Future studies should also account for populations belonging different to Asian ethnicities as well; in an attempt to evaluate racial and/or ethnic variabilities. This will enable the clinicians to better understand and design the "treatment plan phase" 
while considering the esthetic desires of patients.

\section{CONCLUSION}

Within the limitations of our study, the ideal Golden Standard and Golden Proportion values were not found to exist in younger population of Pakistan. It would be clinically more applicable for dental practicioners to use a specific range rather than an absolute value.

\section{CONFLICT OF INTEREST}

None declared

\section{REFERENCES}

1. Hasanreisoglu U, Berksun S, Aras K, Arslan I. An analysis of maxillary anterior teeth: facial and dental proportions. J Prosthet Dent. 2005;94:530-38.

https://doi.org/10.1016/j.prosdent.2005.10.007

2. Wolfart S, Quaas AC, Freitag S, Kropp P, Gerber WD, Kern M. Subjective and objective perception of upper incisors. J Oral Rehabil. 2006;33:489-95.

https://doi.org/10.1111/j.1365-2842.2005.01581.x

3. Azam S, Shahnawaz A, Qureshi. Validity of esthetic proportions in maxillary anterior teeth. Pak Orth J 2014;6: 7-11.

4. Levin EI. Dental esthetics and the golden proportion. J Prosthet Dent. 1978;40:244-52.

https://doi.org/10.1016/0022-3913(78)90028-8

5. Lombardi RE. The principles of visual perception and their clinical application to denture esthetics. J Prosthet Dent. 1973;29:358-82. https://doi.org/10.1016/S0022-3913(73)80013-7

6. Al-Marzok MI, Majeed KR, Ibrahim IK. Evaluation of maxillary anterior teeth and their relation to the golden proportion in Malaysian population. BioMed Central Oral Health. 2013;13:9.

https://doi.org/10.1186/1472-6831-13-9

7. Peixoto LM, Louro RL, Gomes AA, de Nascimento A. Photographic analysis of esthetic dental proportions. Rev Gaucha Odontol. 2012;60:13-7.

8. Ahmed N, Abbas M, Maqsood A. Evaluation of recurring esthetic dental proportion in natural smile of Pakistani sample. Pak Oral Dent J. 2014;34:739-42

9. Mahshid M, Khoshvaghti A, Varshosaz M, Vallaei N. Evaluation of "golden proportion" in individuals with an esthetic smile. J esthet Rest Dent. 2004;16:185-92.

https://doi.org/10.1111/j.1708-8240.2004.tb00032.x

10. Oh Y-A, Yang H-S, Park S-W, Lim H-P, Yun K-D, Park C. Analysis of the width ratio and wear rate of maxillary anterior teeth in the
Korean population. J Adv Prosthodont. 2017;9: 93-8.

https://doi.org/10.4047/jap.2017.9.2.93

11. Hegde MN, Malhotra S. Evaluation of golden proportion between maxillary anterior teeth of south indian population. Dent Open J. 2016;2:137-41.

https://doi.org/10.17140/DOJ-2-125

12. Umer F, Khan FR, Khan A. Golden proportion in visual dental smile in Pakistani population: A pilot study. Acta stomatologica Croatica. 2010;44:168-77.

13. Ong E, Brown RA, Richmond S. Peer assessment of dental attractiveness. Am J Orthod Dentofacial Orthop. 2006;130:163-69. https://doi.org/10.1016/j.ajodo.2005.02.018

14. Wolfart S, Thormann H, Freitag S, Kern M. Assessment of dental appearance following changes in incisor proportions. Eur J Oral Sci. 2005;113:159-65.

https://doi.org/10.1111/j.1600-0722.2005.00206.x

15. Parnia F, Hafezeqoran A, Mahboub F, Moslehifard E, Koodaryan $\mathrm{R}$, Moteyagheni R, et al. Proportions of maxillary anterior teeth relative to each other and to golden standard in tabriz dental faculty students. J Dent Res Dent Clin Dent Prospects. 2010;4:83-6.

16. Bukhary S, Gill D, Tredwin C, Moles DR. The influence of varying maxillary lateral incisor dimensions on perceived smile aesthetics. $\mathrm{Br}$ Dent J. 2007;203:687-93.

https://doi.org/10.1038/bdj.2007.1110

17. Preston JD. The golden proportion revisited. J Esthet Dent. 1993;5:247-51.

https://doi.org/10.1111/j.1708-8240.1993.tb00788.x

18. Alhabahbah AM, Aburumman KK, Al-Shamout R, Almanaseer WA, Zyod AI. Evaluating the validity of mathematical proportions in maxillary anterior teeth in Jordanian population. Pak Oral Dent J. 2016;36:295-300.

19. Al-Kaisy N, Garib BT. Analysis of the golden proportion and width/height ratios of maxillary anterior teeth in Arab and Kurdish populations. J Prosthet Dent. 2018;119:981-86. https://doi.org/10.1016/j.prosdent.2017.08.017

20. Shirinzad M, Ahmady BJ. Evaluation of golden proportion of upper anterior teeth in dental students of Hamedan Dental SchoolIran. J Mash Dent S 2006;30:255-62.

21. Rosenstiel SF, Ward DH, Rashid RG. Dentists' preferences of anterior tooth proportion-a web-based study. J Prosthodont. 2000;9: 123-36.

https://doi.org/10.1053/jopr.2000.19987

22. Ali Fayyad M, Jamani K, Agrabawi J. Geometric and mathematical proportions and their relations to maxillary anterior teeth. J Contemp Dent Pract. 2006;7:62-70. 